ctomy for Wilms' tumor after chemotherapy. BJU Int. 2006; 98: 155-9.

5. Mitchell C, Pritchard-Jones K, Shannon R, Hutton C, Stevens S, Machin D, et al.: Immediate nephrectomy versus preoperative chemotherapy in the management of non-metastatic Wilms' tumour: results of a randomised trial (UKW3) by the UK Children's Cancer Study Group. Eur J Cancer. 2006; 42: 255462.

6. Gommersall LM, Arya M, Mushtaq I, Duffy P: Current challenges in Wilms' tumor management. Nat Clin Pract Oncol. 2005; 2: 298-304.

Dr. F. Tibor Denes

Division of Urology

University of Sao Paulo Medical School

Sao Paulo, SP, Brazil

E-mail:f.c.denes@br2001.com.br

\title{
Re: Prevalence and Associated Factors of Enuresis in Turkish Children
}

\author{
Cuneyt Ozden, Ozdem L. Ozdal, Serkan Altinova, Ibrahim Oguzulgen, Guvenc Urgancioglu, Ali \\ Memis
}

Department of Urology, Numune Education and Research Hospital, Ankara, Turkey

Int Braz J Urol, 33: 216-222, 2007

To the Editor:

In this article, the authors aimed to determine the prevalence and associated factors of enuresis in Turkish children and tried to identify common methods of enuresis management. The sample was drawn using a short but detailed and clear questionnaire distributed to the parents of 1,500 school children aged 6-12 years, covering five schools selected randomly, with a high response rate $(89 \%)$.

Although their overall prevalence of nocturnal enuresis is apparently comparable with previously published epidemiological surveys, the importance of the study is that it demonstrates that enuresis is a frequent disorder in childhood, also in Turkey, although many medical doctors and parents still under- estimate this issue. The traditional concept is that most cases of enuresis are caused by a developmental immaturity of voiding control, and most enuretic children will ultimately acquire normal control with increasing age.

The authors stated that the prevalence of enuresis decreased with age; of the 6-year-old children, $30.8 \%$ still wetted their beds, while none of those aged 12 years did so. These results might suggest a very high spontaneous resolution rate but the figures have to be interpreted with caution since only a small number of children in the age group 6 and $12(n=13$ and 34 respectively) are a major limitation of this study. 
The authors refer to the classical study of Forsythe et al. which dates from 1974 showing a spontaneous cure rate of $14 \%$ annually between the ages of 5 and 9, and $16 \%$ between 10 and 19 years (1). Recently however, Yeung et al. reported no significant drop in prevalence after the age of 10 (2). As age increases there are an increasing proportion of enuretic patients with more severe bedwetting. Enuretic children aged more than 10 years and adolescents, have significantly more daytime urinary symptoms and incontinence compared to younger children (3). Patients with severe symptoms are much more likely to have persistent problems into adulthood. Consequently, it seems that spontaneous cure only applies to patients with rather mild enuretic symptoms. This argues against an expectant and conservative approach towards enuresis. Therefore we are convinced that these recent findings have major clinical implications for both primary and secondary care centers. First of all, enuresis in children aged

\section{REPLY BY THE AUTHORS}

Previous studies demonstrated that the prevalence of enuresis tends to decrease with increasing age, and it was more common in boys than in girls. Similarly, in the present study, $30.8 \%$ of the children were wetting their beds at 6-years-old whereas none of them was wetting their beds at 12-years-old. However, as outlined in the discussion section, a small number of children in the groups of 6-years-old ( $\mathrm{n}=$ $13)$ and 12-years-old $(n=34)$ was the limitation of our study. more than 10 years and adolescents is complex in nature and also in treatment, and therefore these patients should be referred instantly. Second, children with severe or not monosymptomatic nocturnal enuresis have a much lower spontaneous cure rate than generally accepted, making a policy of waiting with appropriate treatment not longer defendable.

\section{References}

1. Forsythe WI, Redmond A: Enuresis and spontaneous cure rate. Study of 1129 enuretis. Arch Dis Child. 1974; 49: 259-63.

2. Yeung CK, Sihoe JD, Sit FK, Bower W, Sreedhar B, Lau J: Characteristics of primary nocturnal enuresis in adults: an epidemiological study. BJU Int. 2004; 93: 341-5.

3. Yeung CK, Sreedhar B, Sihoe JD, Sit FK, Lau J: Differences in characteristics of nocturnal enuresis between children and adolescents: a critical appraisal from a large epidemiological study. BJU Int. 2006; 97 : 1069-73.

Dr. Jo L. Dehoorne

Pediatric Nephrology \& Urology Department University Hospital Gent Gent, Belgium

E-mail: joke.dehoorne@uzgent.be

Dr JL Dehoorne states that enuresis prevalence did not decrease after 10-years-old and with the increasing age the prevalence of severe enuresis increases, referring to the study of Yeung et al. On the other hand, in our study, severe enuresis (bedwetting everyday) rate was $33 \%$, nevertheless, enuresis prevalence decreased with increasing age. Similarly, Serel et al. (1) reported severe enuresis prevalence as $26 \%$ and enuresis prevalence at age 7 and 12 , as $15.1 \%$ and $4 \%$ respectively. Kanaheswari 
et al. (2) demonstrated that the prevalence of bedwetting 2 or more times a week was $54.4 \%$. In their study, they concluded that the rate of enuretic children decreased significantly with increasing age.

We believe that enuresis prevalence decreases as the child grows, however, severe enuresis is a different situation that could be managed separately.

\section{References}

1. Serel TA, Akhan G, Koyuncuoglu HR, Ozturk A, Dogruer $\mathrm{K}$, Unal S, et al.: Epidemiology of enuresis in Turkish children. Scand J Urol Nephrol. 1997; 31: 537-9.

2. Kanaheswari Y: Epidemiology of childhood nocturnal enuresis in Malaysia. J Paediatr Child Health. 2003; 39: 118-23.

\title{
Re: Prevalence and Associated Factors of Enuresis in Turkish Children
}

\author{
Cuneyt Ozden, Ozdem L. Ozdal, Serkan Altinova, Ibrahim Oguzulgen, Guvenc Urgancioglu, Ali \\ Memis
}

Department of Urology, Numune Education and Research Hospital, Ankara, Turkey

Int Braz J Urol, 33: 216-222, 2007

To the Editor:

Authors investigated the prevalence of nocturnal enuresis and associated factors of enuresis in Turkish children. The response rate was $89 \%$ and overall prevalence of nocturnal enuresis and diurnal enuresis were $17.5 \%$ and $1.9 \%$, respectively. Some factors were associated with enuresis. They concluded that the prevalence of nocturnal enuresis in Turkish children was not different form others and that families do not have sufficient attention about enuresis.

First of all, it is hopeful to follow the standardization of terminology of lower urinary tract function in children and adolescents 1 , to make it easier to compare studies and decrease confusion among researchers. The report 1 recommended that the ambiguous term diurnal enuresis should be avoided. Second, when conducting a questionnaire survey, it must be important to use a validated and reliable questionnaire. The major problem, here, is whether the questionnaire was a validated and reliable one or not, to evaluate lower urinary tract symptoms in children. Most of the questionnaire surveys have the same drawbacks as this one: the use of unvalidated questionnaires and no comparative data. Sureshkumar et al. reported the validity and reliability of a questionnaire 2 .

Third, there is no consensus about a simple question that should complete the questionnaire; parents, children or both? In general, it is not so straightforward to evaluate nocturnal enuresis and overactive bladder symptoms accurately in children. For children, it is too difficult to assess the presence of urgency and to count the episodes of nocturnal enuresis and the frequency of daytime voiding. On the other hand, as authors concluded, parents may be unable to report their child's frequency of daytime voiding, presence of urgency and incontinence, and even episodes of nighttime urinary incontinence until 